\title{
Subarachnoid Hematoma
}

National Cancer Institute

\section{Source}

National Cancer Institute. Subarachnoid Hematoma. NCI Thesaurus. Code C116583.

A collection of blood into the space between the pia membrane and arachnoid membrane. 